\title{
Evaluation of Panoramic Radiographs in Relation to the Mandibular Third Molar and to Incidental Findings in an Adult Population
}

\author{
Josefine Cederhag ${ }^{1}$ Nina Lundegren ${ }^{2}$ Per Alstergren ${ }^{3,4} \quad$ Xie-Qi Shi ${ }^{1,5} \quad$ Kristina Hellén-Halme ${ }^{1}$
}

${ }^{1}$ Department of Oral and Maxillofacial Radiology, Faculty of Odontology, Malmö University, Malmö, Sweden

2Department of Oral Diagnostics, Faculty of Odontology, Malmö University, Malmö, Sweden

${ }^{3}$ Department of Orofacial Pain and Jaw Function, Faculty of Odontology, Malmö University, Malmö, Sweden

${ }^{4}$ Specialized Pain Rehabilitation, Skåne University Hospital, Lund, Sweden

${ }^{5}$ Section of Oral and Maxillofacial Radiology, Department of Clinical Dentistry, University of Bergen, Bergen, Norway

Eur J Dent 2021;15:266-272
Address for correspondence Josefine Cederhag, DDS, Department of Oral and Maxillofacial Radiology, Faculty of Odontology, Malmö University, Malmö SE-205 06, Sweden (e-mail: josefine.cederhag@mau.se).

\begin{abstract}
Keywords

- third molar

- panoramic radiography

- incidental findings

- adult

Objectives The aim was to evaluate the characteristics of the mandibular third molars, especially in relation to the inferior alveolar nerve. Further aims were to investigate incidental findings in panoramic radiographs in an adult population, and to investigate image quality related to patient positioning.

Materials and Methods From a previous study with 451 randomly selected adult participants who lived in Sweden, 442 panoramic radiographs from four dental public health clinics were used. The third molars' characteristics and relation to inferior alveolar nerve were evaluated. Incidental findings and patient positioning were recorded. Statistical Analysis Frequency analysis was used to investigate the occurrence of all findings and their possible interconnections. Whether the patients' age or gender had an impact or not was also analyzed.

Results The third molars were erupted and in vertical position among $73 \%$ regardless of age. When retained or semi-retained, they were most commonly in mesioangular positions. The inferior alveolar nerve was located inferior to the roots in 52\%, whereas an overlapped position was most common if the third molar was retained (90\%), semi-retained (83\%) or the age was less than 30 years (66\%). Common incidental findings were apical radiolucencies, idiopathic osteosclerosis, and tooth fragments. Suboptimal patient positioning was found in one-third of the radiographs.

Conclusions Panoramic radiography is a useful method to evaluate third molar prior to surgical removal and may be the only image required. Most incidental findings on panoramic radiographs does not seem to require any further odontological management.
\end{abstract}

published online

December 26, 2020
DOI https://doi.org/ 10.1055/s-0040-1721294 ISSN 1305-7456.
(C) 2020. European Journal of Dentistry.

This is an open access article published by Thieme under the terms of the Creative Commons Attribution-NonDerivative-NonCommercial-License, permitting copying and reproduction so long as the original work is given appropriate credit. Contents may not be used for commercial purposes, or adapted, remixed, transformed or built upon. (https://creativecommons.org/licenses/by-nc-nd/4.0/)

Thieme Medical and Scientific Publishers Pvt. Ltd., A-12, 2nd Floor, Sector 2, Noida-201301 UP, India 


\section{Introduction}

Dental panoramic imaging is a radiological method commonly used in dentistry since 1950s. It is a useful diagnostic tool owing to its broad coverage of teeth, bone, and surrounding anatomical structures in the maxillofacial region. Together with a clinical examination, a panoramic radiograph facilitates the clinician's diagnosis and treatment plan for several diagnostic tasks. It is a two-dimensional radiograph based on the tomographic technique where structures within the image layer are sharply depicted; however, the resolution is lower and less detailed compared with intraoral radiographs. Previous studies ${ }^{1-3}$ have concluded that a majority of exposed panoramic radiographs had certain flaws, of which the most common was related to patient positioning and head alignment. Studies have also shown that a panoramic radiograph has many limitations in terms of diagnostic accuracy. ${ }^{4-6}$

Surgical removal of the third mandibular molars is one of the most common surgical procedures in dentistry. ${ }^{7.8}$ To make a proper assessment of the relationship/proximity between inferior alveolar nerve (IAN) and the roots, a panoramic radiograph is commonly justified. ${ }^{5,9,10}$ However, the possibility to determine a true close relationship between structures has been questioned. ${ }^{4,5} \mathrm{The}$ radiograph has proven to be diagnostically acceptable in most cases to show the location of the third molar and its location to IAN. ${ }^{6}$ Previous studies $^{5,6,11}$ conclude that panoramic radiographs, in many cases, despite the lower resolution, are considered acceptable for a third molar presurgical investigation. The panoramic X-ray unit is well used, the examination is considered convenient by the patients, and importantly, the radiation dose to the patient is considerably lower compared with cone beam computed tomography. ${ }^{10}$ Therefore, the method is considered cost-effective ${ }^{12}$ because the equipment is reasonably inexpensive and the examination time for the patients and dental office is relatively short.

In panoramic radiographs, certain incidental findings of pathology and abnormality may be seen. ${ }^{13}$ Studies have reported the frequency of incidental findings in children, often related to orthodontic treatment. ${ }^{14-16}$ In adults, a few studies have investigated specific incidental findings, such as idiopathic osteosclerosis $^{17}$ and radiolucencies according to apical periodontitis. ${ }^{18} \mathrm{~A}$ new study by MacDonald and $\mathrm{Yu}^{19}$ concluded that in a group of new patients, mixed to permanent dentition, coming for a dental examination, $32.1 \%$ had at least one incidental finding when investigated by panoramic imaging. In a previous study of oral health, panoramic radiographs were exposed in an adult population. ${ }^{20}$ In accordance with and in reference to the radiological principle of As Low As Reasonably Achievable (ALARA), ${ }^{21}$ we believe that the additional evaluation of the already-exposed panoramic radiographs could contribute to further knowledge. Accordingly, a few previous studies ${ }^{17-19}$ evaluated the incidental findings of panoramic radiographs; however, incidental findings in a cross section of adult patients participating for research purpose have not been evaluated.

The aims of this study were to evaluate the characteristics of the mandibular third molars, especially in relation to IAN. Further aims were to investigate the number and kind of incidental findings in panoramic radiographs in an adult population, and to investigate image quality related to patient positioning.

\section{Materials and Methods}

The study was approved by the Ethical Committee for Human Research in Lund, Sweden (Dnr 513/2006).

\section{Study Design}

This observational study included 442 digital panoramic radiographs of 224 (51\%) women and 218 (49\%) men, which were randomly selected from an adult population (age 20-89) living in a south county of Sweden with approximately 1.3 million inhabitants, in 2007. The radiographs were a part of a previous study ${ }^{20}$ and were exposed between 2007 and 2008 at four different dental clinics in a south county of Sweden. All panoramic radiographs were captured by storage phosphor plates then exported in DICOM format ${ }^{22}$ and imported into the viewing program Romexis (Planmeca, Helsinki, Finland). All exposed radiographs were included in the present study.

\section{Evaluation Conditions}

All evaluations were performed under standardized conditions using a display monitor (BARCO; Kortrijk, Belgium) calibrated for the evaluation of radiographic radiographs, with ambient light less than 50 lux. ${ }^{23,24}$ The first 50 radiographs were evaluated together by two observers, one junior radiologist (J.C.), and one senior radiologist in oral and maxillofacial radiology (K.H.H.). The remaining radiographs were evaluated by the first observer (J.C.). If there was any doubt, a consensus was reached by a discussion with the senior radiologist. When needed, the display of the radiographs was adjusted according to personal preferences.

The radiographs were evaluated according to a protocol (-Table 1). In order for the mandibular third molars to be defined as erupted, the main part of the occlusal surface had to be in level with the occlusal surface of the neighboring second molar; semi retained: the crown of the third molar had to be partially covered by bone and for retained: the crown of the third molar had to be completely covered by bone. Incidental findings of pathology and abnormality in the whole radiographs were recorded. Image quality according to patient positioning during exposure was evaluated in coronal plane and to head alignment in relation to the occlusal plane.

\section{Statistical Methods}

Frequency analysis was used to investigate the occurrence of different radiographic findings and their possible interconnections. Whether the patients' age or gender had an impact or not were analyzed using cross-tabulations. To test if any statistically significant difference existed, a chi-square test was used. To be considered as significant the $p$-value was set to 0.05 . Data analyses were performed using the Statistical Package for the Social Sciences (IBM SPSS, version 23 for Windows, Armonk, NY: IBM Corp). 
Table 1 Parameters from examination protocol regarding (A) findings of mandibular third molars and (B) general radiographic findings and image quality parameters

\begin{tabular}{|c|c|c|}
\hline A. & & \\
\hline $\begin{array}{l}\text { Eruption status } \\
\text { Missing } \\
\text { Retained } \\
\text { Semi-retained } \\
\text { Occlusion }\end{array}$ & $\begin{array}{l}\text { Position/angulation } \\
\text { Vertical } \\
\text { Mesioangular } \\
\text { Distoangular } \\
\text { Transversal } \\
\text { Horizontal }\end{array}$ & $\begin{array}{l}\text { Root development } \\
\text { Mineralized } \\
\text { crown } \\
\text { Ongoing root } \\
\text { Development } \\
\text { Closed apex }\end{array}$ \\
\hline $\begin{array}{l}\text { Position of inferior } \\
\text { alveolar nerve } \\
\text { Inferior } \\
\text { Overlapped } \\
\text { Not assessable }\end{array}$ & $\begin{array}{l}\text { Periodontal pocket } \\
\text { Yes } \\
\text { No }\end{array}$ & $\begin{array}{l}\text { Apical } \\
\text { radiolucencies } \\
\text { Yes } \\
\text { No }\end{array}$ \\
\hline \multicolumn{3}{|l|}{ B. } \\
\hline $\begin{array}{l}\text { Incidental findings } \\
\text { of pathology and } \\
\text { abnormality } \\
\text { Yes } \\
\text { No }\end{array}$ & $\begin{array}{l}\text { Patient } \\
\text { positioning in coro- } \\
\text { nal plane } \\
\text { Correct } \\
\text { Anterior } \\
\text { Posterior }\end{array}$ & $\begin{array}{l}\text { Head alignment in } \\
\text { occlusal plane } \\
\text { Correct } \\
\text { Head tilted } \\
\text { upward } \\
\text { Head tilted } \\
\text { downward }\end{array}$ \\
\hline
\end{tabular}

\section{Results}

\section{Mandibular Third Molar}

Of the participants, $58 \%$ had at least one mandibular third molar, and $40 \%$ had both mandibular third molars. The total number was 435 (i.e., 210 participants had tooth 38 and 225 participants had tooth 48 ). The distribution of mandibular third molars in the different age groups is shown in -Fig. 1. A total of $98 \%$ of the teeth showed complete root development. - Fig. 2 shows how the mandibular third molars were erupted in relation to age. In total, $73 \%$ had an erupted location, $12 \%$ had a retained location, and $15 \%$ had a semi-retained location. A vertical position (73\%) was most frequent, but it differed if the tooth was erupted or retained and semi-retained ( - Fig. 3 ).

In $52 \%$ of the teeth, IAN was "located inferior to the roots," followed by "overlapped" and "not assessable," in 40 and $7 \%$, respectively. In the erupted group, $68 \%$ had an inferior location, which was less common in the retained and semi-retained group, where the majority had an overlapped position on the roots (90 and 83\%). The most common location of IAN was inferior in all age groups (40-69\%), apart from the youngest group, where it was in an overlapped location (66\%).

In 10 participants, 11 third molars had apical radiolucencies, 10 of which were found in the erupted group. Eight out of these 10 participants had other pathological findings (such as apical radiolucencies on other teeth or/and tooth fragments). In $20 \%$ of the teeth, a distal periodontal pocket was present, $76 \%$ of those teeth were erupted, and $19 \%$ were semi-retained.

There was no difference between genders in any of the results.

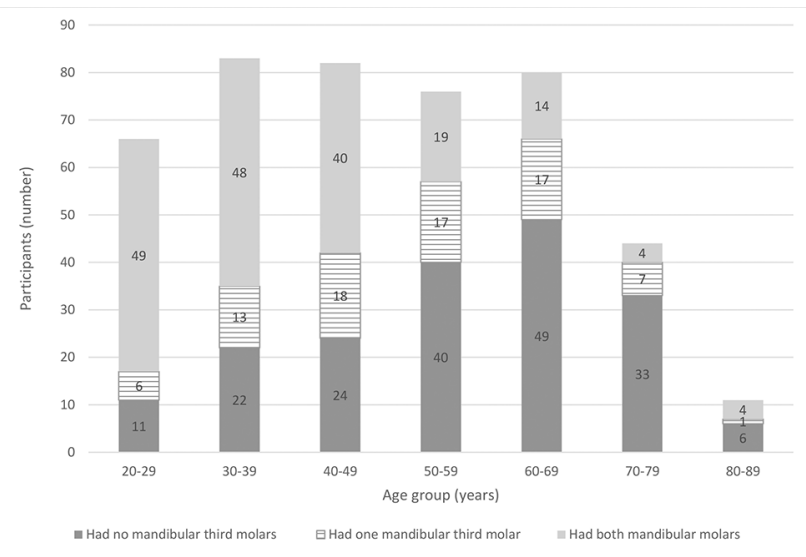

Fig. 1 The distribution of mandibular third molars in the different age groups. Total number of participants $(n=442)$ and third molars $(n=435)$.

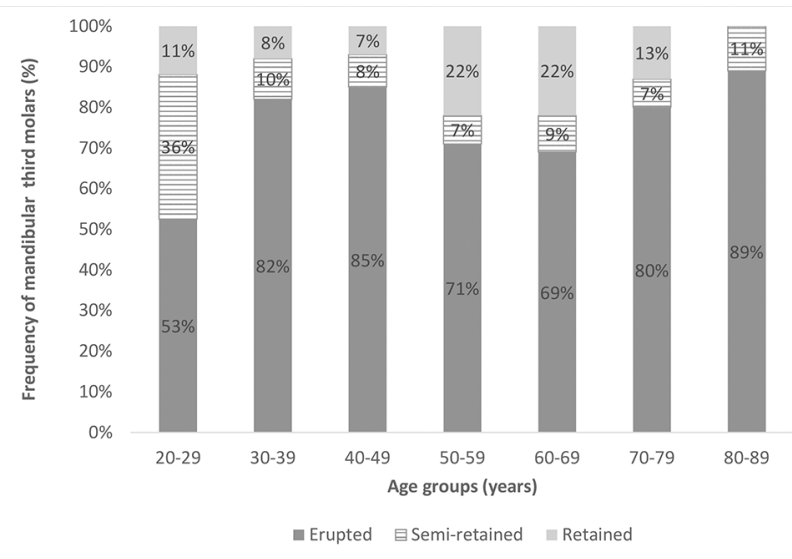

Fig. 2 Mandibular third molars eruption status: erupted/semiretained/retained in the different age groups.

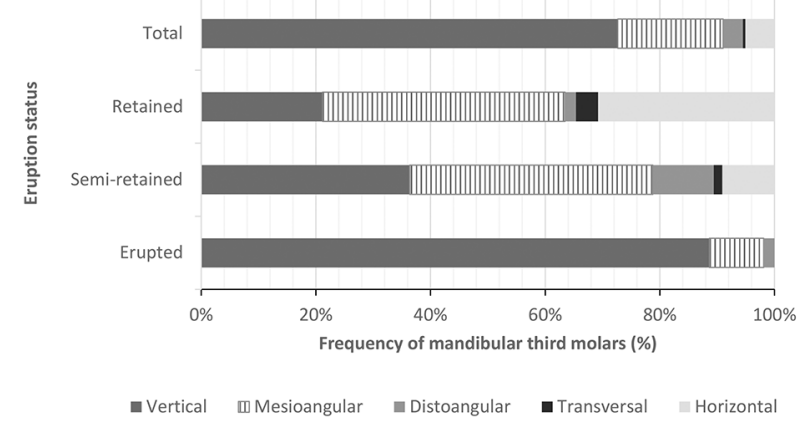

Fig. 3 Mandibular third molars position/angulation in relation to eruption status: erupted/retained/semi-retained, in total and respectively.

\section{Incidental Findings of Pathology and Abnormality}

The total number of incidental findings were 357 and their distribution are shown in - Fig. 4 (A, B). Incidental findings were present in $57 \%(n=252)$ of the participants. There was no difference between genders, and incidental findings 


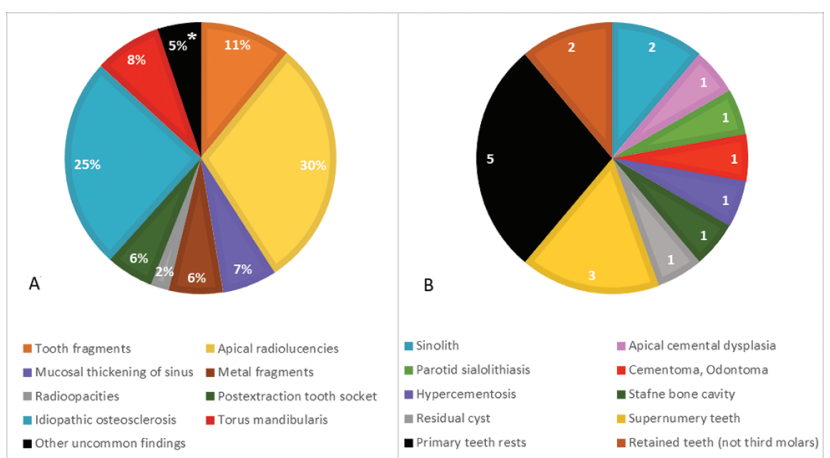

Fig. 4 (A) Incidental findings of pathology and abnormality in percentages of all incidental findings $(n=357)$; (B) Other uncommon incidental findings of pathology and abnormality (6\%) according to -Fig. 4A, in numbers. ${ }^{*}$ These $5 \%$ are shown in relation to specific findings and number in - Fig. 4B.

were present in all age groups but more commonly seen in the older age groups. The most common incidental findings among the participants $(n=442)$ at the individual level were apical radiolucencies in $25 \%$, idiopathic osteosclerosis in $20 \%$, tooth fragments in $9 \%$, and torus mandibularis in $7 \%$.

\section{Image Quality Related to Patient Positioning and Head Alignment}

Patient positioning in coronal plane was correct in $62 \%$ of the patients and head alignment in occlusal plane was correct in $65 \%$. Regarding coronal positioning errors, patients were placed posteriorly of the image layer in $28 \%$ while anteriorly placed in $10 \%$. The corresponding values with respect to head alignment in occlusal plane were 26 and 9\% for head tilted upward and downward, respectively. The periapical status could be evaluated in most of the panorama radiographs, apart from 12 cases where the apical part of the maxillary teeth could not be evaluated properly due to tongue displacement, as the tongue was not in contact with the hard palate during the exposure.

\section{Discussion}

Our results indicate that, in about half of third molars, the IAN is located inferior to the roots of third molars. This was an interesting and important finding since this suggests that in many cases a panoramic radiograph can be enough when investigating a third molar prior to surgical removal. However, if the clinical question asked only is a question about the mandibular third molar, two intraoral radiographs provide a sharp and distinct depiction of anatomical structures with high resolution, but for the patient, it can be challenging to manage a correct receptor positioning in the region. If so, a cropped panoramic radiograph can be a suitable option. Considering the well-known principle ALARA ${ }^{21}$ and radiological European guidelines, ${ }^{10}$ as well as radiation dose, a choice of two-dimensional radiographs can be recommended to exclude a true close relationship between IAN and the third molar. Indeed, panoramic radiographs have been suggested to be justified as the method of choice for presurgical examination to exclude a true close relationship, ${ }^{5}$ i.e., an inferior position of the IAN. This suggestion is in agreement with the results of the present study.

Our study population was randomly selected from adult individuals living in a south county of Sweden in 2007. In the two oldest age groups, considerably fewer individuals chose to participate. ${ }^{20}$ Those groups were included, but when analyzing the result, this factor needs to be viewed accordingly. Nevertheless, apart from the oldest age group, the study sample corresponds well to the age distribution in the county, both at that time and today. ${ }^{20,25}$ In addition, the study sample was selected from a region, taking not only demographic distribution but also representability of ethnicity and educational level into account, and those were, and still are, considered to be adequate..$^{25}$ One limitation, in terms of the radiography, was that the panoramic radiographs were exposed in four different public dental clinics for research purposes about oral health. No specific justifications were made ahead of the exposure of the panoramic radiographs. The exposure was in relation to the aims of that study ${ }^{20}$ and was ethically approved at that time. The different technical settings and supporting devices for patient positioning of each X-ray unit were not known, and thus, the evaluation of image quality was restricted to include patient positioning in coronal plane and head alignment in occlusal plane. The image quality was to some extent flawed in accordance to previous studies, ${ }^{2,26}$ yet, a panoramic radiograph provides a useable overview. More specifically, although many of the evaluated panoramic radiographs were not considered optimal, the mandibular third molar could easily be properly examined. However, the evaluation of apical lesions, especially of maxillary teeth, was impaired in a few radiographs; therefore, the distribution of apical lesions has to be interpreted with caution. Another possible limitation was that only one junior radiologist evaluated all the radiographs. Nevertheless, the evaluation parameters were well defined and did not include diagnostic difficulties. Moreover, when in doubt, a consensus was reached together with a senior radiologist. We therefore do not consider that our examination methodology influences our results.

This study mapped out the characteristics of mandibular third molars in an adult population, from young adults to pensioners, and found that most third molars expectedly, were erupted, had a vertical position, and that IAN was located inferior to the roots. More than half of the study population had one or both mandibular third molars, and not surprisingly, most of those were found in age groups of 50 years and younger. As the dental record was not available, the reasons for a missing mandibular third molar, i.e., previous extraction or absence from birth, are unknown. However, it was often assumed that some in the older age groups had a history of tooth extraction. A study from Finland concluded that only a few third molars survived to old age. However, these findings where only based on clinical assessments. ${ }^{27}$

Erupted third molars seem to be the most common eruption status in all age groups but even more so in those who are in the age group of 30 to 49 years. At this age, the teeth have had time to erupt but may not yet have acquired any 
pathology that would trigger extraction. The participants in the youngest age group had fewer erupted teeth in comparison with the other age groups. In accordance, a relatively large proportion of the semi-retained teeth belonged to the youngest age group, which were teeth under eruption. In the other age groups, the distribution of semi-retained teeth was equally low. In the retained group, the age distribution was quite equal, leading to the conclusion that no matter what age, some teeth are retained and remain so throughout life.

It is difficult to compare our results with other studies, as classification models of impaction, position/angulation, and included age span vary between studies. Nevertheless, Wowern and Nielsen ${ }^{28}$ reported in a 4-year follow-up study, that young people (i.e., 18 years), especially if their tooth was semi-retained, it had a possibility of being erupted as time goes by. Several studies have shown similar findings: depending on erupted status, there was a low to moderate chance for a tooth to become erupted during one's twenties. ${ }^{28-30}$ Another explanation for the equally low number of semi-retained teeth in participants older than 30 years could be that semi-retained teeth in young adults, are at greater risk of pericoronitis, and therefore, had been removed. ${ }^{31}$

The position/angulation of mandibular third molars in relation to eruption status found in this study was as expected. A vertical position was most frequent in the erupted group. However, for the two other groups (retained and semi-retained) mesioangular position was seen the most, even if the differences between mesioangular and vertical position were small among the semi-retained teeth. This equal proportion could be because semi-retained teeth were more likely to be found in the youngest age group with teeth in vertical position, but probably would end in an erupted state. The literature reports that vertically impacted teeth were more likely to erupt in time and also those in the mesioangular and distoangular position, whereas horizontally retained teeth remained unerupted. ${ }^{28,29}$ Ryalat et $\mathrm{al}^{32}$ and Quek et $\mathrm{al}^{33}$ investigated the position/angulation of both retained and semi-retained teeth in a population aged 18 to 26 and 20 to 40 , respectively, and found that mesioangular position/angulation was most common, which is consistent with the results of this study.

If a tooth was erupted or the participants' age was more than 30 years, most had an inferior position of the IAN; however, when a tooth was retained or semi-retained, or the age was less than 30 years, it was most likely that the IAN had an overlapped position. The fact that the youngest age group was the only one where an overlapped position was more common probably because of the large proportion of semi-retained teeth in this age group, with a greater probability for the IAN to have an overlapped position. This is in agreement with Miloro and DaBell, ${ }^{34}$ who concluded that unerupted (both retained and semi-retained) third molars were closer to the IAN than erupted third molars.

The IAN was only evaluated as "not assessable" in considerably few participants. Almost all those teeth were erupted and in vertical position. Previous studies ${ }^{35,36}$ have reported that the best visibility of the IAN in a panoramic radiograph was in the most posterior part of the mandible and diminished with the further anterior location it was; the region of third molars was found to be second best. Furthermore, it was pointed out that the visibility may vary in the same individual, probably because the IAN is situated more buccally in the anterior region. ${ }^{36}$

Ten out of 11 third molars that had apical radiolucencies were erupted and corresponded well to a recent study by Ventä et $\mathrm{al}^{37}{ }^{37}$ who found that third molars in an occlusal level were more likely to be diseased. However, that study had more criteria, including clinical criteria, for being classed as diseased. Hence, the comparison and support for the findings but also the modest number of apical radiolucencies in the present study should be viewed accordingly. An interesting, even though not surprising finding in the present study, was that a majority of the participants had other pathological findings that were preferably found in the older age groups, which was in line with the study by Lundegren et al. ${ }^{20}$

Several incidental findings of pathology and abnormality were present in more than half of the study population, especially in older age groups. However, many of those findings did not require further odontological management. The location in northern Europe could be one possible explanation for this result since Sweden has a national dental insurance system to attract patients to go regularly for a dental examination. According to recent statistics from National Board of Health and Welfare, $69 \%$ of Sweden's adult population did have a regular examination during a 3-year period. ${ }^{38}$ Nevertheless, the most common finding, apical radiolucency, often needs management, indicating that the clinician should be aware of and evaluate the whole radiograph irrespective of question asked, i.e., initial indication for exposure. Even though it has been a while since the radiographs were exposed, it can be assumed that the number and kind of incidental findings in an adult population do not differ extensively over time.

Image quality in panoramic radiographs is dependent on correct patient positioning and head alignment. Several studies $^{1-3,39}$ have concluded that operators' careful handling of technique and training experience, but also patients' cooperating and physical stature, are of great importance to obtain an acceptable panoramic radiograph. The limited dimensions of the focal trough in panoramic imaging has been identified as the weak link. ${ }^{1,3}$ Besides, digital image processing enables image enhancements that were not possible with the analogue technique ${ }^{2}$ and improvements of digital systems have also been made since the panoramic radiographs included in this study were exposed. A notable finding in this study was the poor result of patient positioning and head alignment, where especially coronal posterior and vertical head tilted upward errors dominated. Previous studies ${ }^{3,39,40}$ have reported similar findings, thus confirming the importance of proper handling and correct patient positioning in panoramic radiography.

\section{Conclusion}

This study indicates that panoramic radiography is a useful method for evaluating the relation between the third molar and IAN prior to surgical removal. It may be the only image 
required. In the case of an overlapped position of IAN, other radiological modalities should be considered.

Most incidental findings on panoramic radiographs do not seem to require any further odontological management. However, all radiographic examinations should be fully evaluated regardless of the indication.

Patient positioning seems to be flawed in about one-third of panoramic radiographs.

\section{Conflict of Interest}

None declared.

\section{References}

1 Rondon RH, Pereira YC, do Nascimento GC. Common positioning errors in panoramic radiography: a review. Imaging Sci Dent 2014;44(1):1-6

2 Gross H, Nilsson M, Hellén-Halme K. Detectability of normal anatomy in digital panoramic radiographs. Swed Dent J 2014;38(4):179-185

3 Dhillon M, Raju SM, Verma S, et al. Positioning errors and quality assessment in panoramic radiography. Imaging Sci Dent 2012;42(4):207-212

4 Huang CK, Lui MT, Cheng DH. Use of panoramic radiography to predict postsurgical sensory impairment following extraction of impacted mandibular third molars. J Chin Med Assoc 2015;78(10):617-622

5 Atieh MA. Diagnostic accuracy of panoramic radiography in determining relationship between inferior alveolar nerve and mandibular third molar. J Oral Maxillofac Surg 2010;68(1):74-82

6 Bell GW, Rodgers JM, Grime RJ, et al. The accuracy of dental panoramic tomographs in determining the root morphology of mandibular third molar teeth before surgery. Oral Surg Oral Med Oral Pathol Oral Radiol Endod 2003;95(1):119-125

7 Coulthard P, Bailey E, Esposito M, Furness S, Renton TF, Worthington HV. Surgical techniques for the removal of mandibular wisdom teeth. Cochrane Database Syst Rev 2014;(7):CD004345

8 Cheung LK, Leung YY, Chow LK, Wong MC, Chan EK, Fok YH. Incidence of neurosensory deficits and recovery after lower third molar surgery: a prospective clinical study of 4338 cases. Int J Oral Maxillofac Surg 2010;39(4):320-326

9 Korkmaz YT, Kayıpmaz S, Senel FC, Atasoy KT, Gumrukcu Z. Does additional cone beam computed tomography decrease the risk of inferior alveolar nerve injury in high-risk cases undergoing third molar surgery? Does $\mathrm{CBCT}$ decrease the risk of IAN injury? Int J Oral Maxillofac Surg 2017;46(5):628-635

10 European Commission Radiation Protection $\mathrm{N}^{\circ} 172$ Cone Beam CT for Dental and Maxillofacial Radiology. Evidence-Based Guidelines. Directorate-General for Energy, Directorate DNuclear Energy, Unit D4-Radiation Protection; 2012:1681-6803. Available at: Available at: http://www.sedentexct.eu/files/radiation_protection_172.pdf. Accessed June 30, 2020

11 Bell GW. Use of dental panoramic tomographs to predict the relation between mandibular third molar teeth and the inferior alveolar nerve. Radiological and surgical findings, and clinical outcome. Br J Oral Maxillofac Surg 2004;42(1):21-27

12 Petersen LB, Olsen KR, Christensen J, Wenzel A. Image and surgery-related costs comparing cone beam $\mathrm{CT}$ and panoramic imaging before removal of impacted mandibular third molars. Dentomaxillofac Radiol 2014;43(6):20140001

13 Rushton VE, Horner K. The use of panoramic radiology in dental practice. J Dent 1996;24(3):185-201
14 Bekiroglu N, Mete S, Ozbay G, Yalcinkaya S, Kargul B. Evaluation of panoramic radiographs taken from 1,056 Turkish children. Niger J Clin Pract 2015;18(1):8-12

15 Asaumi JI, Hisatomi M, Yanagi Y, et al. Evaluation of panoramic radiographs taken at the initial visit at a department of paediatric dentistry. Dentomaxillofac Radiol 2008;37(6):340-343

16 Bondemark L, Jeppsson M, Lindh-Ingildsen L, Rangne K. Incidental findings of pathology and abnormality in pretreatment orthodontic panoramic radiographs. Angle Orthod 2006;76(1):98-102

17 Yonetsu K, Yuasa K, Kanda S. Idiopathic osteosclerosis of the jaws: panoramic radiographic and computed tomographic findings. Oral Surg Oral Med Oral Pathol Oral Radiol Endod 1997;83(4):517-521

18 Chala S, Abouqal R, Abdallaoui F. Prevalence of apical periodontitis and factors associated with the periradicular status. Acta Odontol Scand 2011;69(6):355-359

19 MacDonald D, Yu W. Incidental findings in a consecutive series of digital panoramic radiographs. Imaging Sci Dent 2020;50(1):53-64

20 Lundegren N, Axtelius B, Akerman S. Oral health in the adult population of Skåne, Sweden: a clinical study. Acta Odontol Scand 2012;70(6):511-519

21 ICRP. The 2007 Recommendations of the International Commission on Radiological Protection. ICRP publication 103. Ann ICRP 2007;37(2-4):1-332

22 DICOM. Digital Imaging and Communication in medicine. DICOM Grayscale Standard Display Function; 2011. Available at: http://medical.nema.org. Accessed June 30, 2020

23 Hellén-Halme K, Petersson A, Warfvinge G, Nilsson M. Effect of ambient light and monitor brightness and contrast settings on the detection of approximal caries in digital radiographs: an in vitro study. Dentomaxillofac Radiol 2008;37(7):380-384

24 American Association of Physicists in Medicine (AAPM). Task Group 18. Assessment of Display Performance for Medical Imaging Systems. 2006 (updated July 23, 2018). Available at: http://deckard.mc.duke.edu/ samei/samei_tg18/index.html. Accessed June 30, 2020

25 Statistics Sweden (Statistiska centralbyrån). Statistical database. Available at: http://www.statistikdatabasen.scb.se/ pxweb/en/ssd/. Accessed June 30, 2020

26 Akesson L. Panoramic radiography in the assessment of the marginal bone level. Swed Dent J Suppl 1991;78:1-129

27 Suominen-Taipale LNA, Vehkalahti M, Aromaa A. Oral Health in the Finnish Adult Population: Health 2000 Survey. National Public Health Institute; 2008 Kansanterveyslaitos, Finland

28 von Wowern N, Nielsen HO. The fate of impacted lower third molars after the age of 20 . A four-year clinical follow-up. Int J Oral Maxillofac Surg 1989;18(5):277-280

29 Kruger E, Thomson WM, Konthasinghe P. Third molar outcomes from age 18 to 26: findings from a population-based New Zealand longitudinal study. Oral Surg Oral Med Oral Pathol Oral Radiol Endod 2001;92(2):150-155

30 Ventä I. Predictive model for impaction of lower third molars. Oral Surg Oral Med Oral Pathol 1993;76(6):699-703

31 Knutsson K, Brehmer B, Lysell L, Rohlin M. Pathoses associated with mandibular third molars subjected to removal. Oral Surg Oral Med Oral Pathol Oral Radiol Endod 1996;82(1):10-17

32 Ryalat S, AlRyalat SA, Kassob Z, Hassona Y, Al-Shayyab $\mathrm{MH}$, Sawair F. Impaction of lower third molars and their association with age: radiological perspectives. BMC Oral Health 2018;18(1):58

33 Quek SL, Tay CK, Tay KH, Toh SL, Lim KC. Pattern of third molar impaction in a Singapore Chinese population: a retrospective radiographic survey. Int J Oral Maxillofac Surg 2003;32(5):548-552 
34 Miloro M, DaBell J. Radiographic proximity of the mandibular third molar to the inferior alveolar canal. Oral Surg Oral Med Oral Pathol Oral Radiol Endod 2005;100(5):545-549

35 Kamrun N, Tetsumura A, Nomura Y, et al. Visualization of the superior and inferior borders of the mandibular canal: a comparative study using digital panoramic radiographs and cross-sectional computed tomography images. Oral Surg Oral Med Oral Pathol Oral Radiol 2013;115(4):550-557

36 Angelopoulos C, Thomas SL, Hechler S, Parissis N, Hlavacek M. Comparison between digital panoramic radiography and cone-beam computed tomography for the identification of the mandibular canal as part of presurgical dental implant assessment. J Oral Maxillofac Surg 2008;66(10): 2130-2135
37 Ventä I, Vehkalahti MM, Suominen AL. What kind of third molars are disease-free in a population aged 30 to 93 years? Clin Oral Investig 2019;23(3):1015-1022

38 The National Board of Health and Welfare (Socialstyrelsen). Statistik om tandhälsa 2018; 2019. Available at: https://www. socialstyrelsen.se/statistik-och-data/statistik/statistikamnen/ tandhalsa/. Accessed June 30, 2020

39 Rushton VE, Horner K, Worthington HV. The quality of panoramic radiographs in a sample of general dental practices. $\mathrm{Br}$ Dent J 1999;186(12):630-633

40 Ekströmer K, Hjalmarsson L. Positioning errors in panoramic images in general dentistry in Sörmland County, Sweden. Swed Dent J 2014;38(1):31-38 